\title{
Numerical Investigation of Springback in Mechanical Clinching Process
}

\author{
Mohanna Eshtayeh, Meftah Hrairi, and M.S.I Shaik Dawood
}

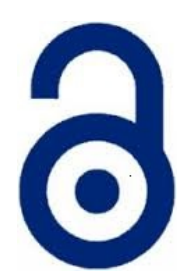

\author{
Received: 09 October 2017 \\ Accepted: 18 November 2017 \\ Published: 10 December 2017 \\ Publisher: Deer Hill Publications \\ (c) 2017 The Author(s) \\ Creative Commons: CC BY 4.0
}

\begin{abstract}
In this work, a numerical investigation was conducted to study the springback phenomena in the mechanical clinching process. The springback values were calculated using finite element simulations and it was found that these values depend strongly on the strength of the materials. A Taguchi optimization method was used to determine the optimal parameters affecting springback. However, in the case of materials with low tensile strength, determining parameters affecting springback becomes difficult. Implicit and explicit simulations of clinching joints using the springback analysis show that the distance between the joint sheets becomes almost zero after stress recovery.
\end{abstract}

Keywords: Clinching, springback, finite element, simulation, optimization, Taguchi method

\section{INTRODUCTION}

Springback is classified as the main defect during the U-channel fabrication process [1]. Springback is generally defined as the dimensional change generated in the part, which occurs due to elastic recovery after the tool is released. In general, springback in metal forming is affected by different factors such as, the mechanical properties (yield strength, elastic modulus) of the metals, tools geometry, and the applied load. In addition, a higher ratio of yield strength and the considerable elastic recovery during unloading lead to springback [2]. Furthermore, the amount of elastic recovery can be affected by the tool shape and dimensions, contact friction condition, material properties, and thickness. In the manufacturing industry, it is still a challenge to predict the final shape of the required part after springback, while the final design of the tool is an important issue in order to compensate for the springback effect. In general, high strength materials have greater springback values during cold forming processes such as U-channel fabrication process, flange drawing process and clinching methods. The finite element method was used to evaluate the springback occurring in the sheet metal flange drawing methods by the control of the punch corner radius, die corner radius, blank holder force, and the lubrication [3]. A numerical investigation was conducted to improve the accuracy of the cold stamping process and to accommodate springback [4]. Springback in sheet metals with a hole on the bending area was investigated using experiments and finite element analysis [5]. The springback introduced with the clinching process showed that springback is a dimensional change between the two sheets forming the clinched joint, after the pressure of the punch and blank holder is released [6]. In addition, the same study showed that the difference between the strain levels produced by the elastic recovery affect the springback values between the two formed sheets. The accuracy of the springback calculation depends on the yield criterion, the hardening behaviour of the sheets after forming the clinched joint, the elastic properties of the two sheets, and the friction properties between the sheets used. A number of numerical experiments was conducted showing the importance of the springback calculations during the forming of the clinched joint [6]. In this paper, a numerical investigation, using

\author{
M. Eshtayeh \\ Deera Metals Industries \\ Technical Support Department \\ P.O. Box 811, Amman 11511, Jordan \\ E-mail: eshteyah_m@yahoo.com \\ M. Hrairi' and M.S.I S. Dawood $\otimes$ \\ Department of Mechanical Engineering \\ International Islamic University Malaysia \\ P.O. Box 10, 50728, Kuala Lumpur, Malaysia \\ 'E-mail: meftah@iium.edu.my \\ 区 E-mail: sultan@iium.edu.my
}

Reference: Eshtayeh, M., Hrairi, M., and Shaik Dawood, M. S. I. (2017). Numerical Investigation of Springback in Mechanical Clinching Process. International Journal of Engineering Materials and Manufacture, 2(4), 86-93. 
the commercial finite element package LS-DYNA, was conducted by performing a procedure to measure the distance between the two sheets after the creation of clinched joints.

\section{METHODOLOGY}

\subsection{Simulation of the Clinching Process}

The experiments were designed using the finite element simulation for the clinching process using springback analysis. Implicit and explicit simulation models were used for the purpose of investigation. A contact was defined between the sheets (deformable) and tools (rigid body) during the clinching forming process. The two blanks to be clinched were simulated using four node quadratic elements. In addition, friction between the two sheets, blank holder, punch, and die has been utilized using Coulomb's law. The most important input data to establish the FE model are; the material properties, the boundary conditions, the displacement versus time for the punch and blank holder movement, stress versus strain data, strain hardening characteristics of the materials, the definition of the contact model, and the absence of residual stresses in the two sheets before loading starts. In LS-DYNA, the updated Lagrange formulation was used due to the large strain and displacement analyses in the clinching forming process. Springback can be calculated in various terms; radius ratio of parts' angles after springback, vertical displacement at the end of the process, etc. Springback analyses by LS-DYNA can be achieved with the interface springback card that allows convenient export of the deformed geometry, stresses, and effective plastic strain from one analysis run to another. The interface card was used to create a DYNAIN file with stress and strain whereas deformed node locations were given. This complicated nonlinear elastic-plastic forming simulation was performed in a relatively shorter time period using a simplified 2D-axisymetric model instead of using a costly 3D model in LS-DYNA. With this feature, various configurations could be modelled and simulated successively, thus saving time and effort.

Figure 1 shows the equivalent Von Mises Stresses and the total equivalent Plastic Strain obtained using FE simulation of the clinching process while Figure 2 shows the Von Mises stress in the Upper sheet (Steel) and lower sheet (Aluminium). The development of stress originates from the contact interface between the punch and upper steel sheet. As the joining force progresses within the time increment, the punch forces the sheets to deform plastically, reducing their initial thickness. With progressing deformation of both sheets their strain hardening ability increases, causing the increase of punch load. Hence, the development of stress starts to progress along the bottom thickness of the upper steel sheet (1.05 GPa) and with a lesser degree in the lower aluminium sheet $(0.8283 \mathrm{GPa})$ as can be seen in Figure 1b and Figure 2.

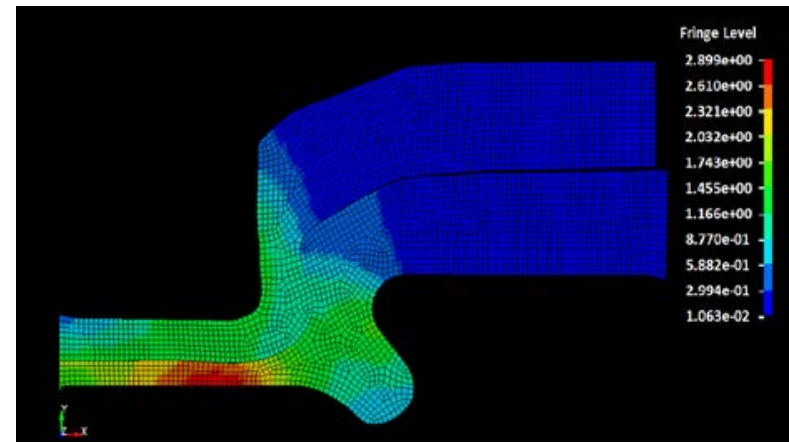

(a) The Effective Strain Fringe Level before springback analysis

Figure 1: The Equivalent Von Mises Stresses and the total Equivalent Plastic Strain obtained from LS-DYNA (2D axis symmetric Clinching forming process)

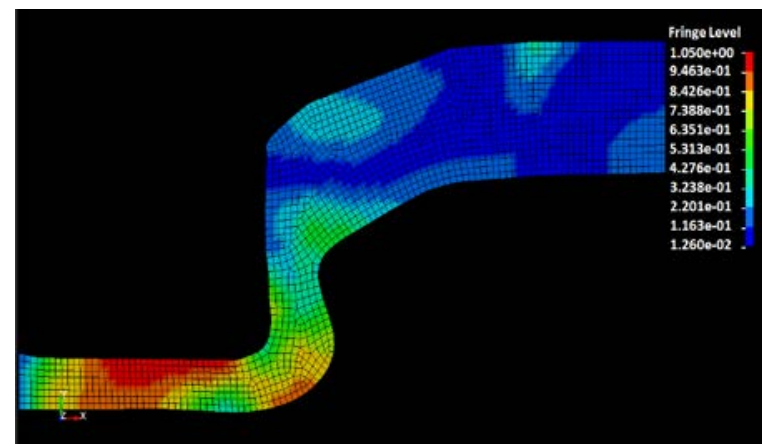

(a) Von Mises Stress for upper sheet (Steel) $1.05 \mathrm{GPa}$

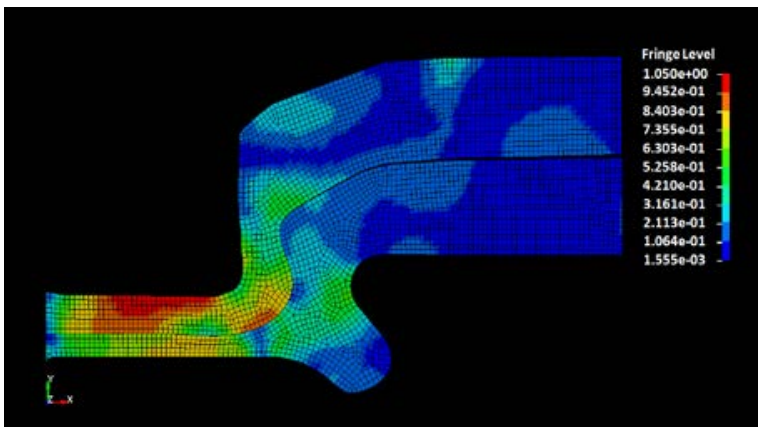

(b) The Von Mises Stresses Fringe Level before springback analysis

Figure 2: Von Mises Stress for Upper and Lower sheets (Steel, Aluminum) shows that higher yield strength material has higher Von Mises values 
As mentioned earlier, springback is a function of the material properties. The larger the strength, the greater the springback will be after forming. In addition, the maximum equivalent plastic strain distribution has a smaller value with higher yield strength. Figure 3 shows the equivalent plastic strain in the clinching joint for the upper sheet (Steel) and the lower sheet (Aluminium). The values show that the equivalent plastic strain after forming in the upper sheet (steel) is smaller than the lower sheet (Aluminium), 1.343 and 2.899, respectively. Another perspective shows that the equivalent plastic strain has a higher value when there is an increase in the sheet thickness.

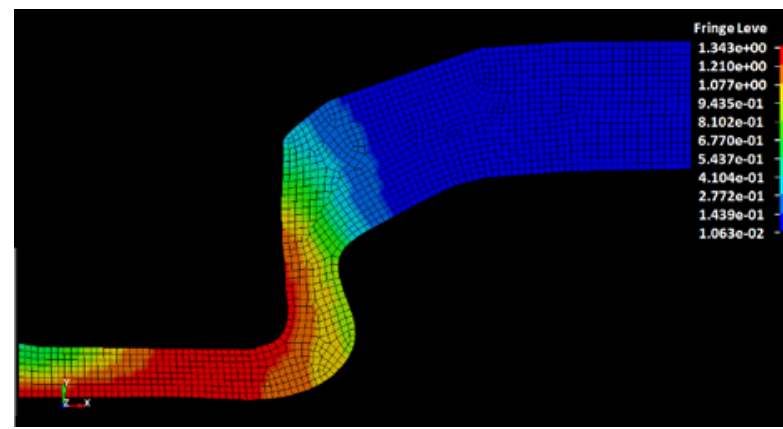

(a) Equivalent Plastic Strain in Upper Sheet (Steel with higher strength than lower sheet)

Figure 3: The Equivalent Plastic Strain in upper and Ic

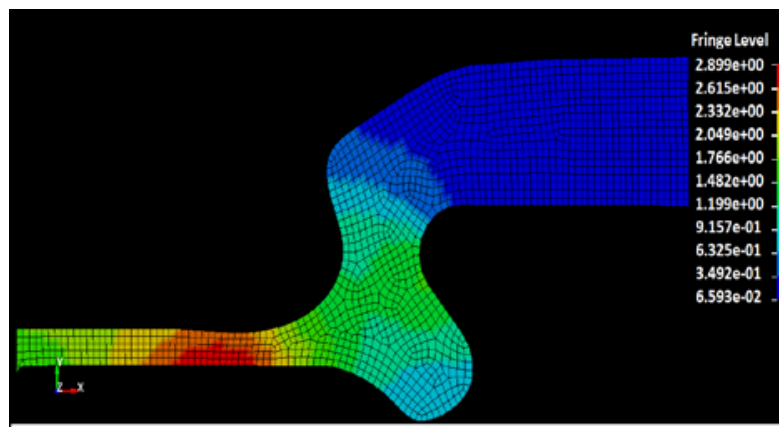

(b) Equivalent Plastic Strain in Lower sheet (Aluminum with lower strength than upper steel sheet) strength

Once the punch moves downward in contact with the upper steel sheet surface, the deformation induced in the surface of the upper blank metal progressively fills the die groove. This was numerically simulated by obtaining the necessary total punch displacement with respect to the time interval. Figure 4 presents the deformed shape of both upper and lower sheets during clinching processes at 25\%,50\%,75\% and $100 \%$ of the assigned punch displacement.

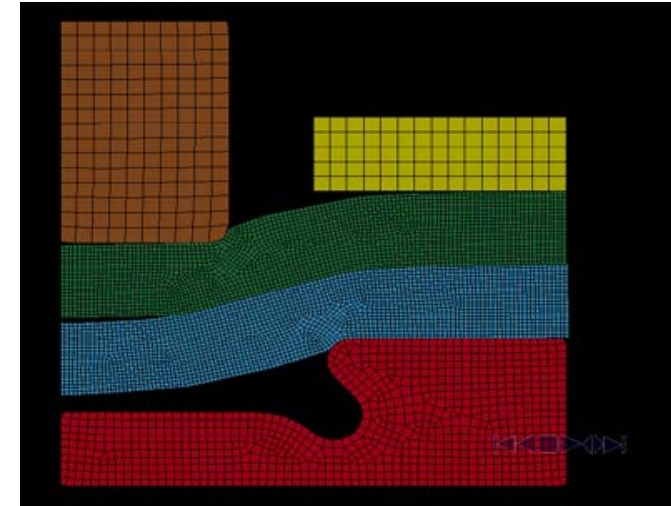

(a) $25 \%$ of the total Punch displacement (initial shear insertion process)

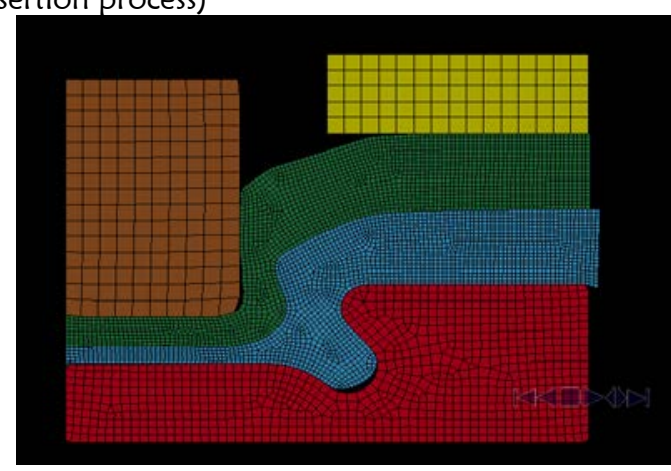

(c) $75 \%$ of the total punch displacement (Filling of the upper die section with complete filling of the ring groove).

Figure 4: Deformed Shape of Both Upper and Lower Sheets During Clinching Processes at Stages 25\%-50\%-75\% and $100 \%$ of the Assigned Punch Displacement

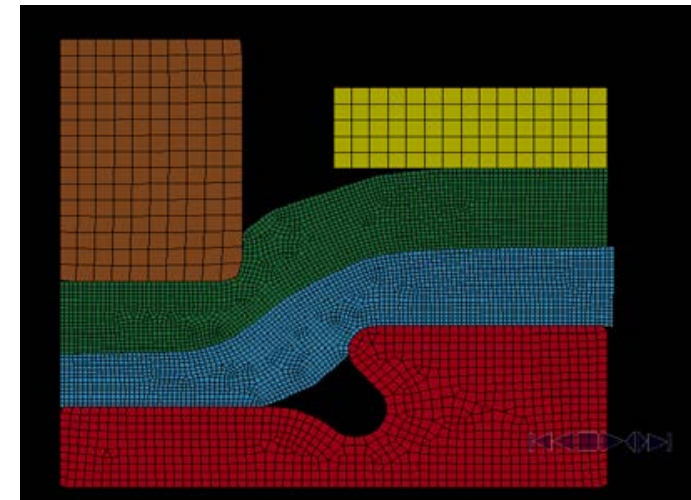

(b) $50 \%$ of the total punch displacement (upsetting and spreading)

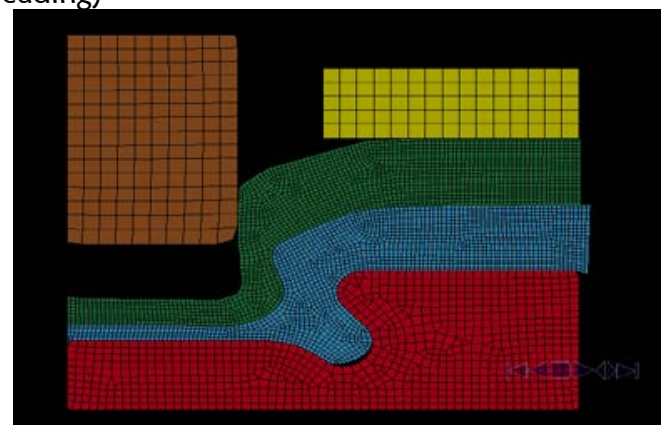

(d) $100 \%$ of the total punch displacement (retraction of the punch - indirect extrusion) 
At $100 \%$ of the punch displacement, the upper steel sheet and the lower aluminium sheet take the shape of the die and any subsequent increase in the displacement of the punch causes an increase in the load. The springback was predicted in terms of the vertical displacement from the total load conditions until the material flow to fill in the die cavity. This is done to induce a different level of plastic strain in both sheets. The punch was later slowly returned to its start position, which gradually allowed the release of the elastic energy. The final shapes of the clinching joint, before and after the release of the load, are shown in Figure 5.

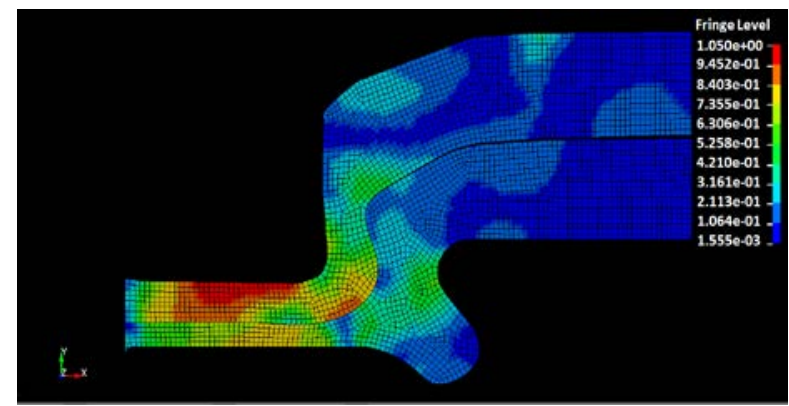

(a) Von Miese Stress before (stress release) springback analysis with value $1.050 \mathrm{GPa}$

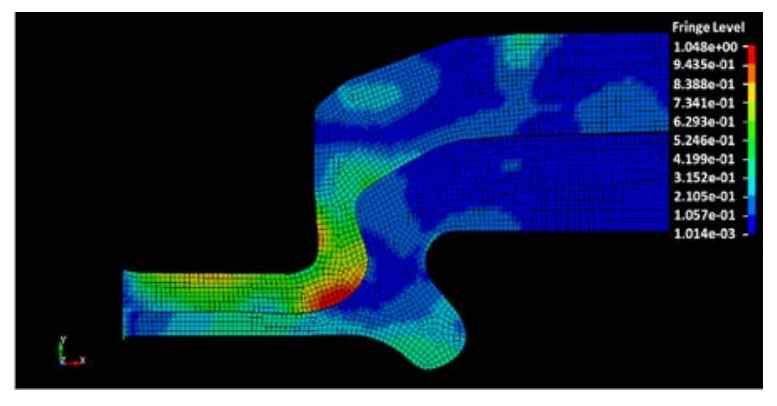

(b) Von Mises Stress after springback analysis with value $1.048 \mathrm{GPa}$ (with stress release)

Figure 5: Final shape of the joint before and after stress release (springback analysis)

\subsection{Taguchi Method}

The Taguchi method is one of the most efficient experimental design tools that test combinations of causes and helps to optimize a process and determine factors that influence variability. The minimum number of experiments, which could give the full information of all the factors that affect the performance parameter, are stipulated by standard orthogonal arrays devised by Taguchi. The signal-to-noise ratio $(S / N)$ is the value of the loss function used to measure the performance characteristic deviation from the desired value. The analysis of the $S / N$ ratio is usually carried out by one of three categories of the performance characteristic, namely, the nominal-the-better, the lower-the-better, and the higher-the-better. Without being affected by the different process parameters, a larger signal to noise $(S / N)$ ratio corresponds to the better performance characteristic.

$$
\mathrm{S} / \mathrm{N}(\text { larger the better })=-10 \log \left(\frac{1}{\mathrm{n}} \sum_{\mathrm{i}=1}^{\mathrm{n}} \frac{1}{\mathrm{y}_{\mathrm{i}}^{2}}\right)
$$

where $\mathrm{n}$ is the number of measurements, $y_{i}$ is the measured characteristic value. The reason behind using the analysis of variance (ANOVA) is to find the clinching process parameters that significantly affect the response or performance characteristics. Generally, this can be achieved by separating the total variability of the response, measured by the sum of squared deviations from the total mean of the response factors, into the contribution from each of the process parameters and the error $[7,8]$. Hence,

where

$$
\mathrm{SS}_{\mathrm{T}}=\mathrm{SS}_{\mathrm{F}}+\mathrm{SS}_{\mathrm{e}}
$$

$$
\mathrm{SS}_{\mathrm{T}}=\sum_{\mathrm{j}=1}^{\mathrm{p}}\left(\overline{\gamma_{\mathrm{j}}}-\gamma_{\mathrm{m}}\right) 2
$$

SST - Total summation of the squared deviations about the mean

$\gamma_{\mathrm{m}}$ - Grand mean of the response

$\gamma_{j}$ - Mean response for the jth experiment $t$

$\mathrm{P}$ - Number of experiments in the orthogonal array

SSF - Sum of square deviation due to each factor

$\mathrm{SS}$ - error of the sum of the squared deviation

Moreover, the F-test was employed to indicate which of the forming parameters had an effective influence on the performance characteristic. Generally, the variation of the process parameter exerts a significant effect on the performance characteristic of the process when the F-test value is large.

\section{RESULTS AND DISCUSSIONS}

As illustrated in Figure 6, there is an opening between the upper sheet and the lower sheet after removing the load of the punch and the blank holder. This gap is due to the springback created from the remaining internal stress of the two sheets. The values of the vertical displacement of the selected element (7202) before and after springback analysis are shown in Figure 7 and Figure 8, respectively. The location of the node after forming, in terms of $x$ and $y$ coordinates, are $3.03973 \mathrm{~mm}, 2.70622 \mathrm{~mm}$ respectively while after springback, the coordinates are $3.03902 \mathrm{~mm}$ and $2.70926 \mathrm{~mm}$. The difference between the two points is very small around $0.00304 \mathrm{~mm}$ in the negative $y$-axis direction. 
Another way to measure the vertical displacement is to measure the change in the vertical distance before and after the springback analysis by taking one node as a reference and same node after recovery of the stress. Figure 9 shows the history of node 8232 with reference to the node coordinate in the $y$-coordinate system. The graph shows that the difference between the two sheets or the opening between the two blanks is around $0.07 \mathrm{~mm}$ in the vertical direction (y). The difference in location of node 8232 before and after springback is very small, which is about $5 \mathrm{e}-$ $4 \mathrm{~mm}$ and $1.87 \mathrm{e}-3 \mathrm{~mm}$ in $\mathrm{x}$ and $\mathrm{y}$ coordinates respectively. The distance is decreased from $0.07 \mathrm{~mm}$ in the vertical direction to be $0.00187 \mathrm{~mm}$ after springback analysis.

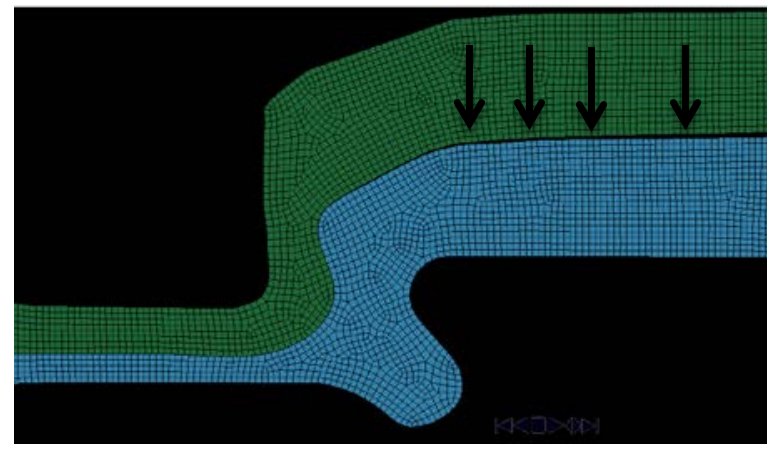

Figure 6: Springback between the two joints before the release of the stress (springback analysis)

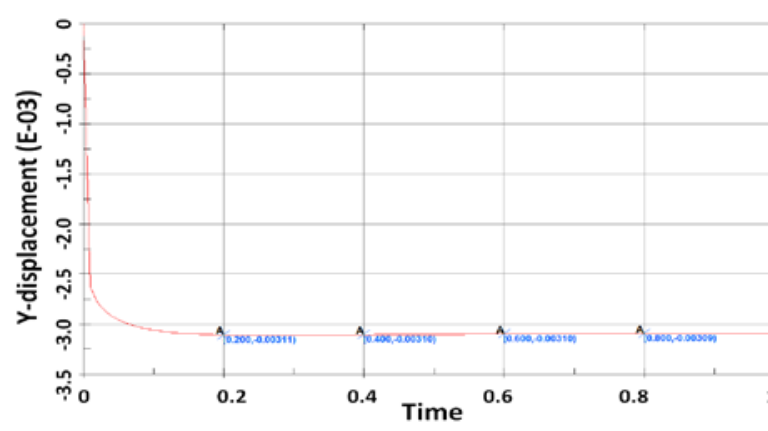

Figure 8: Vertical Y- Displacement of element no. 7202 after springback

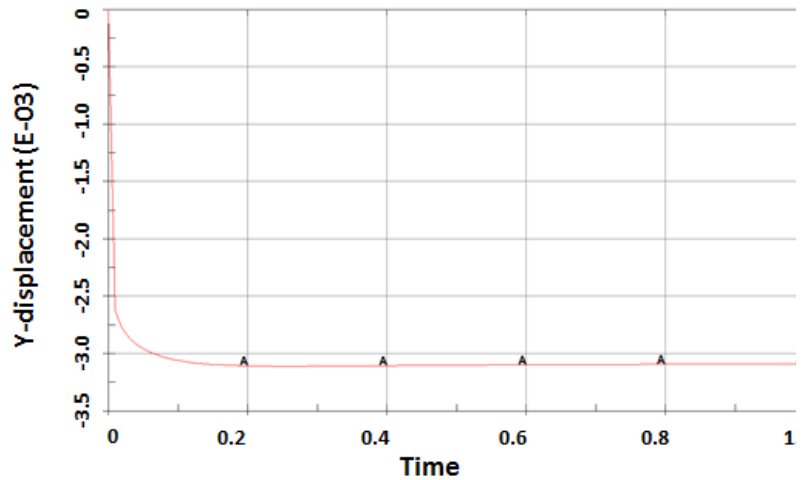

Figure 7: Vertical Y-displacement of element no. 7202 before springback

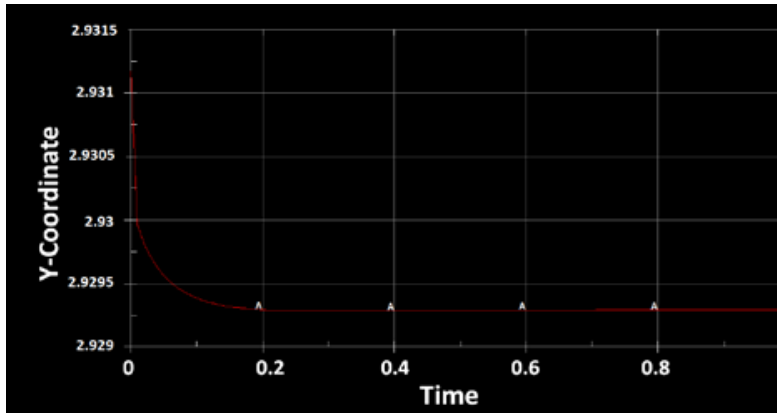

Figure 9: Vertical Y-coordinate system versus time for node 8232

Figure 10 (a) shows the upper sheet with the lower surface before and after springback analysis where the back line showing the lower surface before springback and the red one after springback while Figure 10 (b) shows the lower sheet's upper face before and after. The resultant force between the two parts (upper and lower sheets) is shown in Figure 11, which indicates that the force reached the max value $0.15 \mathrm{kN}$. After $0.1 \mathrm{~m}$-sec the force started to decrease to a value of $0.14 \mathrm{kN}$ with $0.2 \mathrm{~m}-\mathrm{sec}$, after which it gradually levelled at approximately $0.13 \mathrm{kN}$. The stability of the resultant force between the two blanks gives an indication that there is an interlock between the two parts.

The Taguchi method was used to investigate the most important parameters affecting the springback analysis using the implicit simulation technique as an experiment. Taguchi's L27 orthogonal array design and the notion of signal to noise $(S / N)$ ratio were utilized to obtain the objective function. Analysis of variance (ANOVA) showed the importance of factors on overall output. The output of the study showed that there are no main parameters affecting the springback. It may be worth changing the materials used as the clinched sheets to high tensile steel or stainless steel in order to have higher springback values. Indeed, the die groove height, die diameter, punch diameter, punch corner radius and clearance between punch and blank holder were found to be the most influential parameters on the bottom and neck thicknesses for the clinching process[9]. Table 1 shows selected simulation results from the 27 simulations of the springback process. The distance between the two sheets after the explicit simulation was almost zero. 


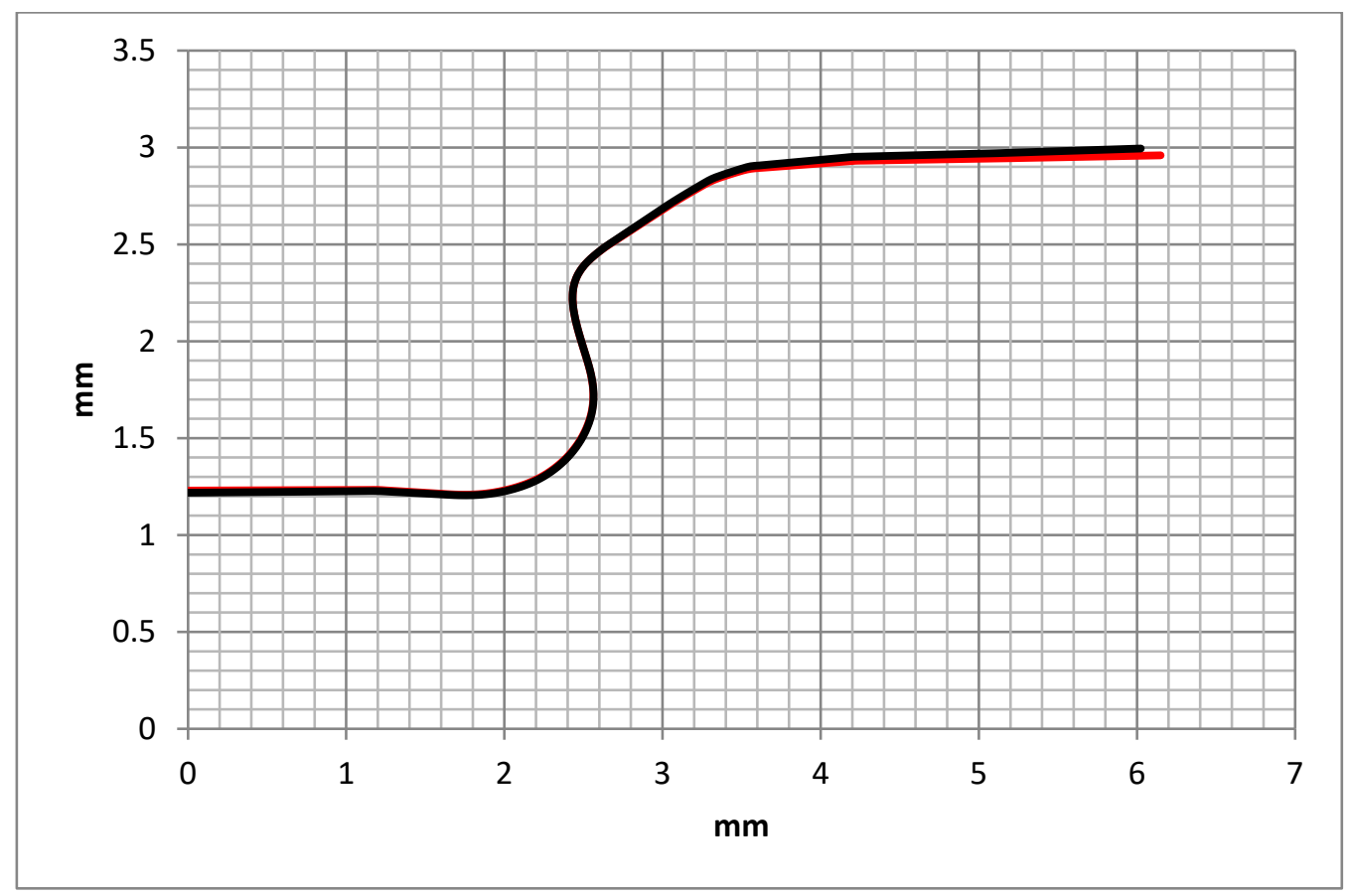

(a) Upper sheet lower surface before and after springback analysis (Red line shows after Spring back, where Black one before)

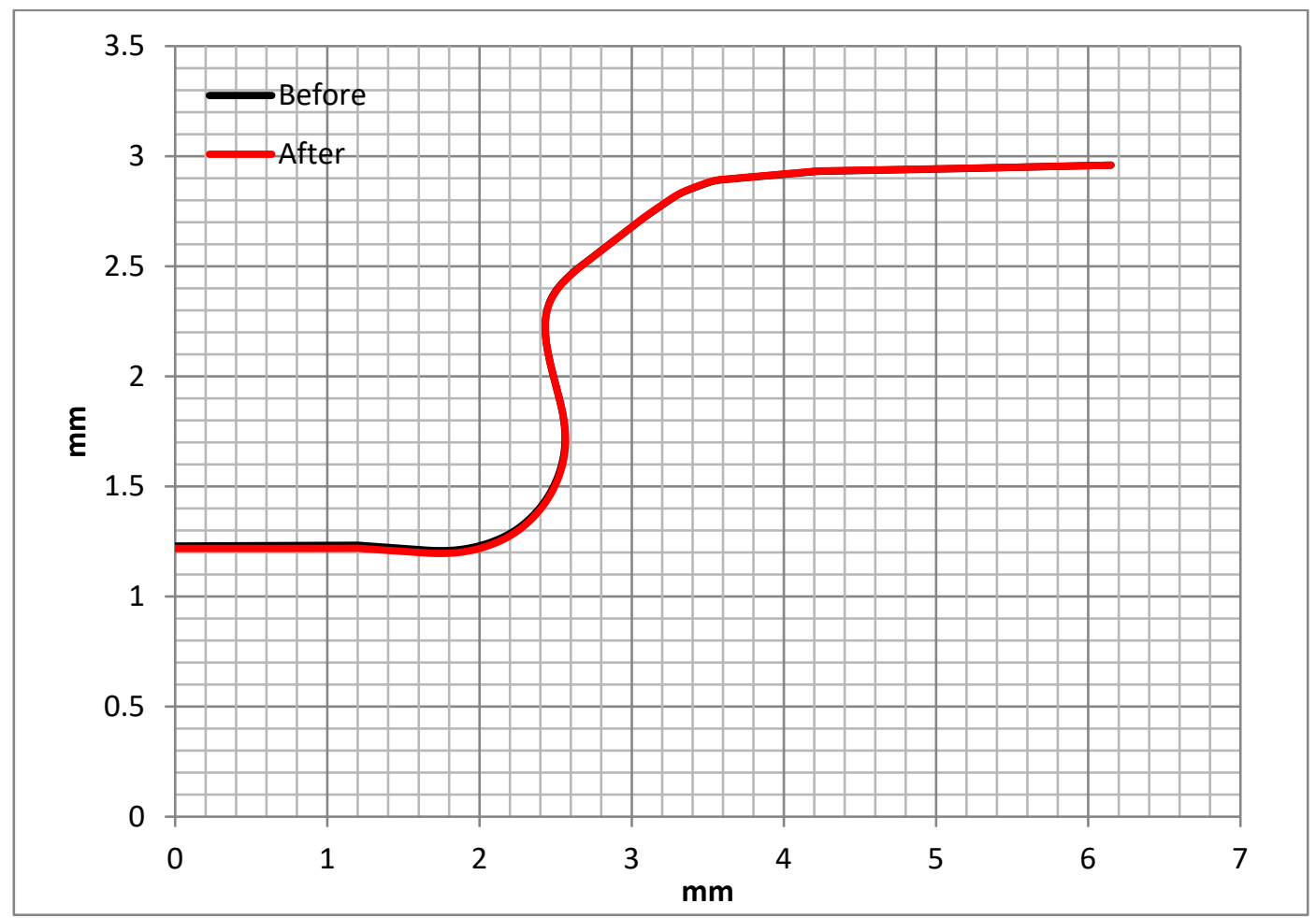

(b) Lower sheet upper face before and after springback (Black line before, Red after)

Figure 10: Springback analysis for upper sheet lower face and lower sheet upper face 


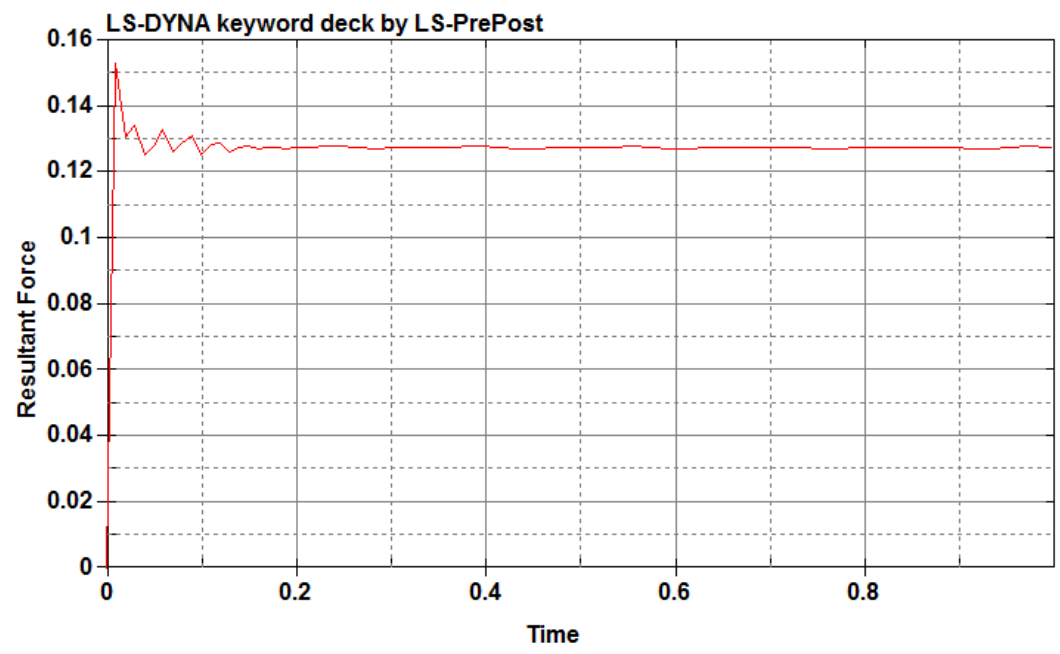

Figure 11: Resultant force between the upper and lower parts with time.

Table 1: Sample results of the orthogonal array L27 of the clinching simulation and springback.

\begin{tabular}{|c|c|c|c|c|c|}
\hline \multirow{2}{*}{$\begin{array}{l}\text { Exp. } \\
\text { No. }\end{array}$} & \multicolumn{4}{|c|}{ Simulation output } & \multirow{2}{*}{$\begin{array}{l}\text { Springback Analysis } \\
\text { (Explicit Analysis) } \\
\text { Stress flow contour after stress } \\
\text { release }\end{array}$} \\
\hline & $x$ & th & & $\begin{array}{l}\text { Stress flow contour during } \\
\text { clinching process }\end{array}$ & \\
\hline 1 & 0.847 & 0.358 & 0.101 & & \\
\hline 9 & 0.859 & 0.362 & 0.027 & & \\
\hline 18 & 0.845 & 0.400 & 0.041 & & \\
\hline 27 & 1.237 & 0.256 & 0.01 & & \\
\hline
\end{tabular}

\section{CONCLUSIONS}

In this paper, the finite element modelling of the clinching methods and springback analysis were discussed. The fixed type of die was investigated using LS-DYNA commercial software. The friction was assumed to be constant between the areas of contact using Coulomb's law. To save computational effort the simulations were carried out using 2Daxisymmetric modelling approach. The high plasticity during the forming of the joint establishes a large element distortion creating numerical problems during the simulation, where the adaptive remeshing option was used to overcome this problem. The results using the springback analysis show the possibility of calculating the springback 
values (opening between the two sheets after forming the joints) between the two sheets. The optimization of the clinching process to indicate the optimal parameters affecting the springback between the two sheets can be obtained using the Taguchi optimization methods.

\section{REFERENCE}

1. Kadkhodayan, M. and I. Zafarparandeh (2009). An investigation into the influence of blankholder force on springback in u-bending. Archives of Metallurgy and Materials, 54(4), 1183-1190.

2. Nikhare, C. (2012). A Numerical Approach on Reduction of Young's Modulus during Deformation of Sheet Metals. Modeling and Numerical Simulation of Material Science, 2(01), 1-13.

3. Lee, S.-W. and Y.-T. Kim (2007). A study on the springback in the sheet metal flange drawing. Journal of Materials Processing Technology, 187, 89-93.

4. Siswanto, W.A., et al. (2014). An alternate method to springback compensation for sheet metal forming. The Scientific World Journal.

5. Nasrollahi, V. and B. Arezoo (2012). Prediction of springback in sheet metal components with holes on the bending area, using experiments, finite element and neural networks. Materials \& Design (1980-2015), 36, 331336.

6. Coppieters, S., et al. (2011). Reproducing the experimental pull-out and shear strength of clinched sheet metal connections using FEA. International Journal of Material Forming, 4, 429-440.

7. Mondal, S., et al. (2013). Application of Taguchi-based gray relational analysis for evaluating the optimal laser cladding parameters for AISI1040 steel plane surface. The International Journal of Advanced Manufacturing Technology, 66(1-4), 91-96.

8. Datta, S., A. Bandyopadhyay, and P.K. Pal (2008). Grey-based taguchi method for optimization of bead geometry in submerged arc bead-on-plate welding. The International Journal of Advanced Manufacturing Technology, 39(11-12), 1136-1143.

9. Eshtayeh, M. and M. Hrairi (2016). Multi objective optimization of clinching joints quality using Grey-based Taguchi method. The International Journal of Advanced Manufacturing Technology, 87(1-4), 233-249. 